\title{
A case of successful conception after Jone's metroplasty in woman with recurrent pregnancy loss with septate uterus
}

\author{
Jaydeep Bhatu*, Hina Ganatra
}

Department of Obstetrics and Gynecology, GMERS Medical College and Hospital, Sola, Ahmedabad, Gujarat, India

Received: 14 March 2020

Accepted: 04 April 2020

\section{*Correspondence:}

Dr. Jaydeep Bhatu,

E-mail: bhatujaydeep@gmail.com

Copyright: (C) the author(s), publisher and licensee Medip Academy. This is an open-access article distributed under the terms of the Creative Commons Attribution Non-Commercial License, which permits unrestricted non-commercial use, distribution, and reproduction in any medium, provided the original work is properly cited.

\begin{abstract}
Anomalies of the reproductive tract are common and are seen in approximately 3-5\% of the general population. These are usually asymptomatic, but are sometimes associated with recurrent pregnancy loss or infertility. Among these anomalies, septate uterus is the most common anomaly to be associated with obstetric complications and infertility. A 27 years old female patient P0A2L0 with first spontaneous abortion at 3 months and second spontaneous abortion at 4 months came to OPD with complaint of recurrent pregnancy loss. She was advised USG of pelvic region which shows septate uterus with normal cervix, fallopian tubes and ovaries. Patient prepared for DHL complete septum present normal $\mathrm{B} / \mathrm{L}$ ostium and Jone's metroplasty done in which wedge shaped incision kept on uterine fundus, common cavity created by un roofing septum myometrium closed and AT the end Copper T 375 placed in intrauterine cavity for 6 months. 1 year after surgery patient came with UPT positive for antenatal visit at sola civil. Patient is now with 30 weeks of pregnancy with normal single intrauterine live cephalic fetus, metroplasty is an accepted method of treatment in women with recurrent abortions and septate uterus and it significantly improves the subsequent reproductive outcome. combined data from several published series and reported that the incidence of spontaneous abortion and preterm delivery rate decreases significantly after metroplasty, whereas, the incidence of term delivery rate increases.
\end{abstract}

Keywords: Jone's metroplasty, Recurrent pregnancy loss, Septate uterus

\section{INTRODUCTION}

Anomalies of the reproductive tract are common and are seen in approximately $3-5 \%$ of the general population and approximately $3 \%$ of infertile women. ${ }^{1}$ These are usually asymptomatic, but are sometimes associated with recurrent pregnancy loss or infertility. Among these anomalies, septate uterus (class V, American fertility classification, based on the study by Buttram and Gibbons), is the most common anomaly to be associated with obstetric complications and infertility. ${ }^{2}$ Resection of the septum helps to improve pregnancy outcome in these women. ${ }^{3}$ Cervical agenesis with vaginal septum with uterine anomalies (12\%) responsible for primary amenorrhea. $^{4}$
Moreover, it is unclear whether the prognosis differs in septate and sub septate uteri, and few studies have investigated the relation between obstetric history before and after surgery so we represented these case report. ${ }^{2}$

\section{CASE REPORT}

A 27 years old female patient P0A2L0 with first spontaneous abortion at 3 months and second spontaneous abortion at 4 months came to OPD with complaint of recurrent pregnancy loss. On examination per abdomen was soft and non-tender. On per speculum cervix and vagina healthy. Per vaginally on bimanual examination uterus was anteverted and normal size. Patient advised USG of pelvic region USG shows septate 
uterus with normal cervix, fallopian tubes and ovaries. Patient was prepared for DHL

On intra-operative findings and procedure, laproscopy normal size uterus with mild concavity at fundus. Normal ovaries and fallopian tubes and in hysteroscopy complete septum present normal B/L ostium (Figure 1).

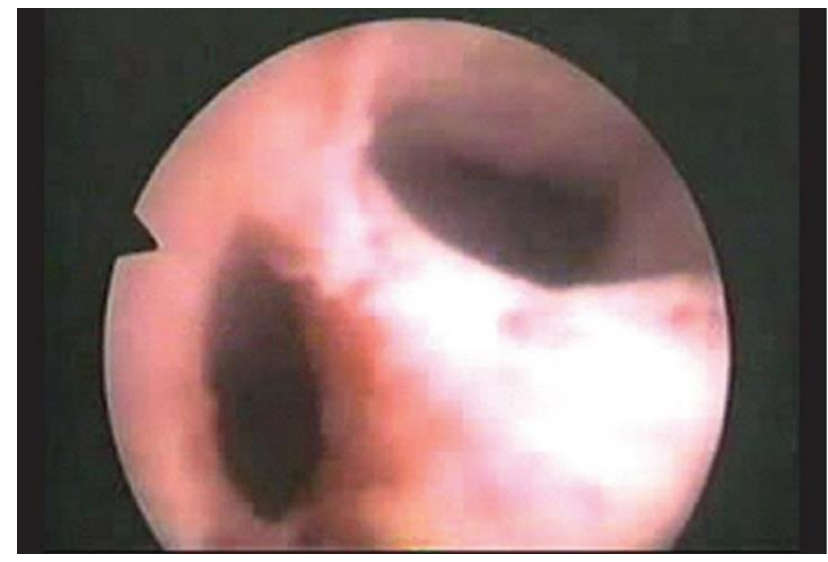

Figure 1: Hysteroscopy view: bi cornuate uterus with two ostia seen.

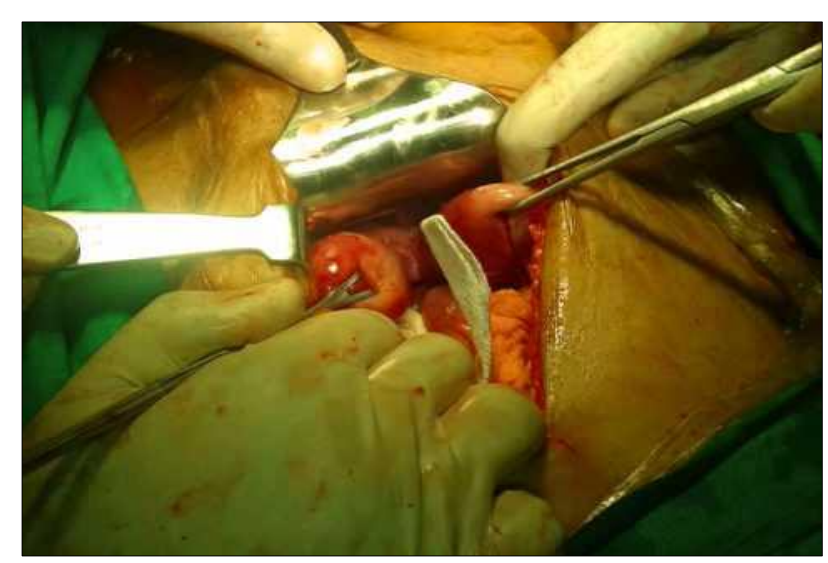

Figure 2: Open view of pre-operative bicornuate uterus.

\section{Outcomes}

Intra-operative decision to do Jone's metroplasty done in which Wedge-shaped incision kept on uterine fundus, common cavity created by unroofing septum myometrium closed with interrupted stiches with vicryl number 0 . Remaining layer closed with continuous manner with vicryl number 1 . Copper T 375 placed intrauterine for 6 months (Figure 2). 1 year after surgery patient came with UPT positive for antenatal visit at sola civil. Patient is now with 30 weeks of pregnancy with normal single intrauterine live cephalic fetus.

\section{DISCUSSION}

Septate uterus is the most common uterine anomaly to be associated with poor reproductive performance. The exact mechanism by which this anomaly causes recurrent abortions or infertility is not clearly established.

Diminished size of the uterine cavity and cervical incompetence, associated with septate uterus, may be the factors involved in causing a poor reproductive outcome.

Fedele et al, reported that the septal wall consists of fibroelastic tissue with alterations in the endometrial myometrial blood vessels, which cause a negative impact on placental development. ${ }^{5}$

Pabuccu et al, reported that cervical cerclage was in $(11.1 \%)$ and in $(44.4 \%)$ of the 9 who did not have a cerclage had preterm deliveries. As after metroplasty chances of preterm delivery also high. And (66.6\%) who had live births were delivered by cesarean section and we will selectively be planned for elective cs in our patient at 37 weeks after steroid coverage. ${ }^{6}$

\section{CONCLUSION}

Metroplasty is an accepted method of treatment in women with recurrent abortions and septate uterus and it significantly improves the subsequent reproductive outcome. combined data from several published series and reported that the incidence of spontaneous abortion and preterm delivery rate decreases significantly after metroplasty, whereas, the incidence of term delivery rate increases.

\section{ACKNOWLEDGMENTS}

Authors would like to thank Dr. Swati Patel, who was also operated the patient and Dr. Ajesh Desai for giving so much guidance and Dr. Jaya Varu for scripting and language correction.

\section{Funding: No funding sources Conflict of interest: None declared \\ Ethical approval: The study was approved by the Institutional Ethics Committee}

\section{REFERENCES}

1. Tonguc EA, Var T, Batioglu S. Hysteroscopic metroplasty in patients with a uterine septum and otherwise unexplained infertility. Inter $\mathbf{J}$ Gynecol Obstet. 2011;113(2):128-30.

2. Buttram VC, Gibbons WE. Müllerian anomalies: a proposed classification (an analysis of 144 cases). Fertil Steril. 1979;32(1):40-6.

3. Saygili-Yilmaz E, Yildiz S, Erman-Akar M, Akyuz G, Yilmaz Z. Reproductive outcome of septate uterus after hysteroscopic metroplasty. Arch Gynecol Obstet. 2003;268(4):289-92.

4. Bhatu JJ, Bhadaraka GB. Study and clinical evaluation of 25 cases of primary amenorrhea. Int $\mathbf{J}$ Reprod Contracept Obstet Gynecol. 2020;9(2):667. 
5. Fedele L, Bianchi S, Marchini M, Mezzopane R, Nola GD, Tozzi L. Residual uterine septum of less than $1 \mathrm{~cm}$ after hysteroscopic metroplasty does not impair reproductive outcome. Human Reprodu. 1996;11(4):727-9.

6. Pabuçcu R, Gomel V. Reproductive outcome after hysteroscopic metroplasty in women with septate uterus and otherwise unexplained infertility. Fertil Steril. 2004;81(6):1675-8.
Cite this article as: Bhatu J, Ganatra H. A case of successful conception after Jone's metroplasty in woman with recurrent pregnancy loss with septate uterus. Int J Reprod Contracept Obstet Gynecol 2020;9:2208-10. 